\title{
BUSCANDO RÁIZES
}

\section{Antônio Greco Rodrigues \\ Centro Universitário de Belo Horizonte - Brasil}

Resumo: $O$ artigo tem como objetivo discutir a origem do conhecimento que forma a base da medicina popular brasileira. Procuramos mostrar como esse conhecimento chegou até nosso povo e como foi aceito por ele. A discussão está centrada na forma pela qual elementos da medicina hipocrática são encontrados em noções expressas aqui, tais como os de natureza do corpo, das doenças ou dos alimentos $e$, principalmente, no conceito de reima e reimoso.

Palavras-chave: Antropologia do corpo e da saúde, Brasil, medicina popular.

Abstract: This article investigates the origin of the knowledge which forms the basis of Brazilian popular medicine. in: an attempt to understand how this knowledge arrived and was accepted by Brazilians, the discussion is centered on the way in: which elements of Hippocratic medicine are to be found in: notions such as the nature of the body, illness, foods, and particularly in: the concept of reima and reimoso.

Keywords: Brazil, folk medicine, Medical Anthropology.

Em qualquer sociedade, saúde e doença são temas que atraem a imediata atenção das pessoas. Problemas com o sistema público de saúde ou os planos de saúde e novas descobertas em medicina ocupam grande espaço em jornais e têm atenção garantida na programação de televisão. Para algumas pessoas, a preocupação em compreender as causas das doenças, os tratamentos e os cuidados necessários para evitá-las chega a ser uma obsessão, assumindo caráter patológico. Isso é comum em todas camadas da sociedade, mas manifesta-se de forma diferenciada conforme o tipo de informação de que as pessoas dispõem. Nosso interesse está voltado para o conhecimento que as pessoas sem formação médica nem acesso aos recursos terapêuticos disponíveis na sociedade moderna têm dessas questões. Ele está reunido em um grande acervo de saberes e práticas sobre doença, cura 
e prevenção que chamamos medicina popular. É o saber tradicional, que passa de pessoa a pessoa, fora do sistema acadêmico, constituindo o recurso tradicional dos que não têm acesso à medicina formal ou nela deixaram de crer.

Como qualquer outro campo do saber, a medicina popular tem seus profissionais que detêm um acervo particularmente grande de conhecimento ou são possuidores de uma virtude particular, como os raizeiros, as benzedeiras ou os curandeiros. Entretanto esse é um universo onde não existe a apropriação exclusiva do saber por parte desses especialistas. Ele é partilhado por todo o grupo. Tanto podemos encontrá-lo no trabalho do raizeiro que faz seus remédios a partir dos vegetais nativos que recolhe no campo, como na seleção de ervas medicinais cultivadas nas sacadas dos apartamentos de uma metrópole. Esse saber partilhado faz da mãe de família o principal agente terapêutico da medicina popular. Ela a tem como o recurso primeiro em qualquer doença que apareça em sua casa, até que possa ter acesso a um médico (Castro Rodrigues, 1979).

Quando estudamos a medicina popular no Brasil, uma das primeiras questões com que nos deparamos é descobrir de onde surgiram esses saberes e sua relação com as múltiplas influências que formaram a cultura brasileira. Pretendemos iniciar a discussão pela classificação que Foster (1976) fez dos sistemas de medicina popular. Ele tomou como base a explicação que cada povo dá para a origem das doenças e, conforme a interpretação que predomina em cada sociedade, classificou-os em personalísticos e naturalísticos. Quando o conhecimento e as crenças sobre saúde e doença estão associados principalmente ao universo mágico-religioso, o sistema é dito personalístico. Quando as doenças são compreendidas como originadas de forças naturais, os sistemas são chamados naturalísticos.

Nos sistemas personalísticos, a doença é conseqüência da ação proposital de um agente, que pode ser humano (como um feiticeiro), não humano (um fantasma, um ancestral ou um espírito demoníaco) ou sobrenatural (uma divindade ou outro ser muito poderoso). A pessoa doente é literalmente uma vítima, objeto de agressão ou punição. Esse tipo de explicação predomina entre as populações tribais, especialmente as africanas.

Nos sistemas naturalísticos, o indivíduo não é vítima, mas agente de sua própria doença. Ela é sempre conseqüência de ações da pessoa que adoeceu: o que fez, o que comeu, onde esteve. Ou seja, se uma pessoa adoece, tem de haver em seu comportamento mais ou menos próximo do 
evento algo que explique o aparecimento do problema, pois, conforme esses princípios, compreender a etiologia da doença é buscar uma ação que lhe tenha dado origem. $\mathrm{O}$ que se quer saber é por que a pessoa adoeceu, não o processo pelo qual a doença se instala e se desenvolve. Por isso, busca-se a causa da doença pela análise, a posteriori, das ações do doente. Nelas se encontrará a explicação para o aparecimento da doença.

Embora dêem explicações diferentes para a origem das doenças, ao enfocar tratamento e cura, ambos os sistemas estão fortemente ligados ao mágico-religioso. Mesmo doenças compreendidas como originadas de causas naturais dependem da vontade divina para serem curadas, pois a saúde é um estado ideal que dificilmente pode ser conservado e, uma vez perdido, só pode ser recuperado por intervenção divina. Do contrário, a pessoa recupera-se daquela doença, mas não volta a ser saudável como era antes. $\mathrm{O}$ problema imediato pode ser solucionado por recursos oriundos da medicina popular ou da medicina acadêmica, mas a cura definitiva só pode vir de Deus, de quem o agente de saúde é um intermediário. Por isso, os tratamentos são profundamente ritualizados e, quando se preparam ou se aplicam os remédios, eles são cercados de procedimentos místicos ou mágicos que visam lhes dar a virtude que cura.

O sistema dominante na medicina popular brasileira é o naturalístico. Embora tenha recebido muitas contribuições dos diversos grupos negros e indígenas que participam da formação cultural do Brasil, ela é, em sua essência, um saber que veio com o colonizador português, sendo facilmente rastreado até a medicina praticada na Europa daquela época. Sua origem remota está no saber médico da Grécia antiga, na medicina hipocrática. Os princípios da medicina hipocrática, especialmente a noção do equilíbrio como fundamento da manutenção da saúde, formam a base da explicação das doenças na nossa medicina popular ${ }^{1}$. Conforme essa teoria, são os humores que, pelo equilíbrio de suas qualidades, devem manter o organismo sadio. A doença é a ruptura desse equilíbrio. Ela se instala quando uma das qualidades do corpo humano ganha predomínio sobre as outras pela ação de um agente interno ou externo. Essa condição varia de pessoa a pessoa; conforme prepondere a natureza quente, fria, seca ou úmida em cada indivíduo.

1 Veja sobre esse tema Currier (1966), Foster (1953), Lloyd (1964), Logan (1973) e Taylor (1963). 
Na origem dessa discussão, está a forma de explicar a construção do universo através da compensação por pares opostos, oposições naturais, como vida e morte, direita e esquerda, macho e fêmea, luz e trevas, acima e abaixo, com forte conteúdo simbólico. A elas juntam-se categorias religiosas, como puro e impuro ou abençoado e amaldiçoado. Esse tema tem sido muito discutido pelos antropólogos e é parte essencial da cosmologia grega clássica. Podemos encontrá-lo também no sistema simbólico de outros povos, tanto que Hipócrates (460-377 a.C.) não foi o único a destacar a importância do equilíbrio das forças existentes no organismo humano como fundamento de um sistema explicativo da relação entre a saúde e a doença. Essa explicação pode ser encontrada em outras culturas onde as oposições que reúnem elementos naturais, aos quais se atribui significado simbólico, são parte fundamental da cosmologia, como na medicina chinesa tradicional e em muitas culturas tribais. Mas é a partir da medicina grega que se pode traçar uma linha nítida de transmissão dessas idéias até a medicina popular brasileira.

Os mais antigos textos gregos em que se encontra explicitada a explicação da natureza por pares opostos são fragmentos dos escritos de Anaxágoras (450 a.C.), onde ele a relaciona a luz, trevas, terra e sementes presentes na mistura original, quando todas as coisas estavam juntas. Entretanto, ela já era importante no pensamento especulativo dos gregos antigos, em escritos anteriores a Parmênides (540 a.C.) e não se limitava às questões de saúde.

Empédocles correlacionava certos pares de opostos com algumas de suas raízes, desenvolvendo um esquema bastante complexo. O sol, por extensão o fogo, é descrito como brilhante e quente e a chuva, por extensão a água, como escura e fria. Os outros dois elementos essenciais da natureza, terra e ar, não são caracterizados por ele com a mesma clareza.

O quente, o frio, o seco e o úmido, sós ou em conjunção com outros pares de opostos, aparecem em dois tipos de teorias físicas. A primeira ocorre quando eles mesmos figuram como elementos: substâncias primárias de que as coisas são compostas, como Hipócrates mostra em A Natureza do Homem. A segunda surge quando eles são associados aos elementos, quando são concebidos na forma de outras substâncias, como Hipócrates mostra em Do Corpo. 
Embora essas oposições não estejam necessariamente relacionadas a condições naturais, elas são categorias simbólicas criadas por um sistema de relações com o sol, o solo ou a chuva. Em sua gênese, representam a relação entre o homem e a natureza. As classificações estão baseadas no conceito que estabelece que as pessoas, doenças, medicamentos, comidas e a maioria dos objetos naturais têm natureza. Assim, a prática médica consistia em compreender a natureza do paciente, determinar a natureza da doença e restaurar a harmonia fundamental que foi desarranjada.

Hipócrates afirmava que há dois elementos que compõem todas as criaturas vivas, o fogo e a água, e que, ao morrer, todos os componentes do corpo humano retornam à sua própria natureza.

Ele descreveu quatro humores básicos: o sangue que é quente e úmido; o catarro que é frio e úmido, a bile negra que é fria e seca e a bile amarela que é quente e seca. São eles que determinam o equilíbrio de forças necessário para a manutenção da higidez do organismo. Ter saúde depende de um organismo equilibrado e isso só é possível quando nenhum fator prepondera sobre os outros. Os três principais órgãos do corpo são: o coração seco e quente, o cérebro úmido e frio e o fígado úmido e quente; o que faz com que o organismo tenda a estar mais próximo do quente que do frio, especialmente nas mulheres, uma vez que elas têm mais um órgão quente, o útero.

Hipócrates atribuiu as doenças tanto a essas oposições diretamente quanto ao seu efeito em outras substâncias ou partes do corpo. Ele afirmava que o sofrimento é causado tanto pelo quente quanto pelo frio, tanto quando eles estão em excesso, como quando estão em falta. Dizia ainda que as doenças são causadas pela bile e o catarro, quando eles provocam muita secura ou muita umidade, muito calor ou muito frio no corpo.

Segundo esses princípios, as doenças também eram classificadas como frias ou quentes: erupções e outras doenças, compreendidas como vindas de dentro do corpo para fora, são ditas quentes; doenças das vias respiratórias, entendidas como vindas de fora do corpo para dentro, são ditas frias.

A oposição seco - úmido se perdeu no caminho pelo qual esses conceitos chegaram até nós. A forma reduzida, a oposição quente - frio, foi identificada em vários estudos realizados no Brasil e em toda a América Latina. 
Foi longo e tortuoso o caminho pelo qual o melhor pensamento científico da Antigüidade penetrou no saber popular latino-americano. No século XVI, a medicina da Península Ibérica era o resultado de múltiplas influências: as crenças celtas, os princípios da medicina grega e romana, o uso das preces e bênçãos cristãs e as crenças mouriscas. A medicina baseada nas práticas gregas predominava nesse tempo das conquistas. Entretanto, ela não tinha chegado aos povos ibéricos diretamente de seus criadores, mas através dos árabes que a aprenderam, desenvolveram e divulgaram, principalmente através da influência de alguns grandes médicos que criaram escolas importantes, como Rhazes (850-925) e Avicena (980-1037). Eles preservaram os conhecimentos de medicina hipocrática, a primeira a mostrar que a doença tem causas naturais e que seu estudo e a ação médica correspondente não podem se limitar ao aspecto mágico religioso.

A transferência dos componentes da cultura ibérica para o novo mundo aconteceu através de mecanismos formais e informais. O Estado e a Igreja elaboraram planos formais para orientar a política colonial, ao mesmo tempo em que o contato com os povos nativos adaptavam os costumes ibéricos à nova realidade.

Os físicos, como então eram chamados os médicos, estavam entre os primeiros exploradores do novo mundo. Tinham como objetivo pesquisar a flora e a fauna da nova terra, que classificaram de acordo com o sistema que conheciam e compreendiam. A farmacopéia indígena teve seus elementos estudados e classificados de acordo com os princípios hipocráticos.

O pensamento de Hipócrates, Galeno e Avicena fundamentava o ensinamento nas primeiras escolas médicas criadas no México e no Peru, para tentar suprir a deficiência de médicos, insuficientes para a extensão do território, o que levava ao enorme prestígio que tinham entre as famílias os guias de medicina doméstica.

Essa visão da medicina prevaleceu até o final do século XVIII, garantida pelo relativo isolamento da Península Ibérica e das colônias iberoamericanas com relação ao pensamento científico que se desenvolveu no norte da Europa. Ali a medicina ainda era pensada e praticada conforme os princípios dos precursores por pelo menos um século depois que eles já eram considerados ultrapassados por toda a Europa.

A história da medicina no Brasil começou quando surgiu a necessidade de prover a assistência da medicina européia aos primeiros colonos. É evi- 
dente que esse começo foi bastante precário, principalmente pela falta de médicos, que eram praticamente inexistentes nos primeiros anos da colônia (Santos Filho, 1977).

A assistência médica no Brasil começou com os jesuítas, que organizaram ambulatórios junto a seus colégios e igrejas, onde a população, especialmente a mais pobre, era atendida. $\mathrm{O}$ atendimento era feito pelos padres e irmãos, pois, embora fossem raros os médicos formados entre eles, todos recebiam um treinamento básico que os habilitava a um trabalho correspondente ao de um auxiliar de enfermagem. Além disso, como mostram documentos da época, eles levavam os médicos, por ventura existentes nas cidades, a prestar assistência gratuita em seus ambulatórios. Impossibilitados de contar em seus ambulatórios com os recursos que usavam na Europa, os jesuítas procuraram substituí-los pelos que podiam encontrar na nova terra. Para isso, dedicaram-se a aprender com os índios o uso das plantas e demais recursos de sua medicina tribal, adaptando-os às suas próprias idéias sobre tratamento e cura. Esse sistema vigorou até a expulsão da Companhia de Jesus das terras brasileiras.

A ação governamental na assistência médica durante a Colônia e o Império era antes uma não ação. A medicina no Brasil dividia-se entre a medicina privada, só acessível à camada privilegiada da população e a medicina caritativa, exercida principalmente através de associações parareligiosas como as Misericórdias, pois o Estado limitava sua ação quase só a campanhas periódicas de saúde pública, praticamente não agindo no âmbito da assistência ao doente. Essa situação permaneceu até o início do século XX e alterou-se somente quando apareceu a assistência médica previdenciária.

Ao longo de todo esse tempo, diante da ausência de um sistema organizado de assistência médica pública, o atendimento à população era feito principalmente por leigos e curiosos que se apropriavam do saber médico tradicional e o utilizavam de acordo com suas possibilidades. Não é difícil identificar o processo que colocou esse acervo de conhecimento ao alcance de nossa população rural. Ainda é possível localizar, guardados como relíquias de família, alguns exemplares dos livros que foram utilizados como manual de consulta para todos os tipos de problemas relativos à saúde, lavoura ou tempo, como o Lunário Perpétuo e o Dicionário de Medicina Popular de Chernowiz. O Lunário Perpétuo, embora não tenha mais a 
mesma importância, ainda é, através de um calendário baseado em seus princípios que é editado em Mariana (MG), uma espécie de guia do homem do campo mineiro. O Dicionário de Medicina Popular, usado por muitas mães de família do século XIX e início do século XX, é uma versão resumida do Formulário do mesmo autor e que, construído com base em princípios da medicina humoral e utilizando muitos conhecimentos da flora medicinal brasileira, foi manual de farmacologia nas escolas de Medicina e Farmácia desde 1843 até os primeiros anos do século XX. Ele ainda pode ser encontrado em muitas farmácias, especialmente aquelas localizadas em pequenas cidades, como orientador do trabalho dos seus donos, geralmente práticos que, embora não tenham formação universitária, são importantes porque suprem a ausência de médicos, ainda hoje raros no interior.

Os procedimentos de diagnose e terapêutica que hoje são considerados como característicos da medicina popular eram, portanto, o que de melhor havia na medicina científica até o século XIX. Os médicos diagnosticavam e tratavam apenas com base nos sintomas, sabendo pouco ou nada da etiologia da maior parte das doenças. As descobertas que mudariam a face da medicina ainda não haviam acontecido ou não tinham obtido a necessária difusão para que fossem realmente incorporadas ao dia-a-dia do trabalho médico. O conhecimento dos microorganismos e de sua ação, bem como o da célula e da ação das glândulas, aconteceu na segunda metade do século XIX e a bioquímica celular e a imunologia só nas duas últimas décadas do século XX deixaram de ser tratados como uma curiosidade científica. Por outro lado, a maior parte dos medicamentos hoje prescritos pelos médicos foram desenvolvidos a partir de 1930 (Calder, 1976).

A medicina formal abandonou aqueles conhecimentos tradicionais, substituindo-os pelas descobertas recentes que a transformaram. Entretanto, novas teorias passam lentamente dos pesquisadores que as criam para o povo. Por isso, o conhecimento popular sobre saúde, doença e terapia continua ligado ao saber tradicional fundamentado em um dos princípios da medicina hipocrática: a necessidade de manter o equilíbrio das forças antagônicas que convivem dentro do organismo. Corpo sadio é aquele que se mantém perfeitamente sintonizado, conjugando eficientemente o seu estado de equilíbrio interno com a sua ação externa, pelos esforços que pratica ou pelos alimentos que absorve. As formas de explicar doenças se conformam à tradição hipocrática do diagnóstico, que considera os alimentos, o frio, o sol e os ventos como causa de doenças.

Horizontes Antropológicos, Porto Alegre, ano 7, n. 16, p. 131-144, dezembro de 2001 
As doenças do tempo são relacionadas às condições climáticas, em especial ao ciclo das estações. O sarampo, a pneumonia, a coqueluche, a cachumba, a varicela e a gripe são as mais comuns e uma prova irrefutável, para nossos informantes, dessa natureza climática é o fato de que essas doenças sempre têm caráter epidêmico. Ao lado delas, encontramos a constipação que é explicada como sendo provocada por um choque térmico sobre o corpo do indivíduo. Esse choque dá-se, especialmente, quando o corpo aquecido recebe um brusco resfriamento. Ele é o elemento explicativo para as mais variadas doenças desde simples resfriado até tuberculose, lepra, câncer ou leucemia. É importante atentar para o fato de que os elementos essenciais do choque térmico são o sol e o vento; a constipação sempre será mais séria quando o corpo foi aquecido pelo sol e resfriado por uma súbita lufada de vento, o golpe de ar. A constipação e as doenças do tempo parecem-me ligadas ao mesmo princípio básico: a relação do organismo com o ambiente externo e a capacidade agressiva desse ambiente.

Os alimentos, ao mesmo tempo que nutrem, protegem e garantem a manutenção do equilíbrio, têm, se mal usados, a capacidade de agredir o organismo, provocando ou agravando doenças, pela relação de sua natureza com a natureza do corpo. A explicação para isso deve ser buscada não só nas categorias classificatórias de alimentos, mas também na relação do alimento com o corpo humano (Polgar, 1963).

O corpo humano e a comida constituem um sistema de trocas diretas e efeitos recíprocos (Brandão, 1976). Isso permite estabelecer uma correlação constituída de três elementos: alimento/consumidor/efeito que estará na raiz da explicação das doenças causadas pelo alimento.

A compatibilidade do corpo com o alimento deve ser entendida como a capacidade que o organismo tem para resistir ao seu efeito. Cada pessoa reagirá de maneira diferente, conforme sua condição orgânica, à capacidade agressiva dos alimentos. Esse potencial de agressividade está ainda condicionado à forma como eles são consumidos e, principalmente, preparados. Alimentos cozidos são menos perigosos que alimentos crus. Comer várias coisas ao mesmo tempo - a comida na mesa ou as frutas numa salada - é menos perigoso que comer uma e depois a outra. A ordem em que se come também é importante: se o alimento mais indigesto é comido antes, a mistura pode ser perigosa; se é comido depois, o risco diminui. 
Essa explicação cobre também a recomendação de sobriedade alimentar, pois o comer além da quantidade considerada normal ou o juntar, num espaço de tempo curto, vários alimentos diferentes e em grande quantidade, representa também uma sobrecarga ao organismo e contribui para o surgimento das doenças.

Ao tentar compreender como funciona o sistema explicativo das doenças provocadas pelo alimento, nenhum conceito parece-me ser tão adequado quanto o de alimento reimoso ${ }^{2}$. Ele está associado à classificação dos alimentos conforme os princípios da medicina humoral, mas é muito mais complexo que a classificação em quentes ou frios, fortes ou fracos, pois, enquanto essas qualidades são parte da natureza do alimento, o ser reimoso não o é. A condição de reimoso, atribuída a um alimento, não é permanente e não é a mesma em qualquer circunstância, como são as demais qualidades. Ela nasce da relação do alimento com o organismo que o ingere e é só por essa relação que ganha sentido.

Uma das principais dificuldades encontradas na tentativa de entender o que seja um alimento reimoso é que a população pesquisada não tem um conceito claro de reima ou de reimoso. Quando inquiridos, respondem sempre com exemplos de comidas que são reimosas e, se interrogados por que a comida é reimosa, as respostas não formam um padrão explicativo. Essa complexidade aumenta porque não existem apenas comidas reimosas, mas comportamento reimoso (andar a cavalo, subir escada para mulheres puérperas, pisar sem sapatos no chão molhado ou ficar perto do fogo). Além disso, muitas doenças (como o sarampo) deixam reima, depois de curadas. Reimoso ainda pode significar desonesto, aproveitador e manhoso para se referir a pessoas.

Como conciliar todos esses significados tão diversos dentro de uma explicação coerente? O que é reima? Etimologicamente reima ou reuma origina-se do grego e significa a corrente de um líquido ou o fluxo de um humor orgânico, enquanto reimoso é definido como aquilo que provoca a reima. O que primeiro ressalta é o significado etimológico da palavra reima: sua associação à teoria dos humores para explicar as doenças. Assim, se reima é o fluxo dos humores, reimoso será aquele alimento ou atitude capaz

\footnotetext{
2 No Norte e no Nordeste a expressão reimoso costuma ser substituída por carregado.
} 
de perturbar esse fluxo. Essa associação encontra base nos relatos dos informantes e parece confirmada por dados obtidos na literatura existente sobre reima.

É bastante claro que a idéia de reima está presa ao fluxo de líquidos orgânicos. Tanto o alimento reimoso quanto os comportamentos reimosos estão relacionados a ocasiões onde esses fluxos, de caráter normal ou patológico, aparecem: menstruação, puerpério, distúrbios intestinais, ferimentos ou expectoração. Em todas essas ocasiões, quando os humores internos são expostos, o organismo mostra-se mais vulnerável e o alimento reimoso possui a capacidade potencial de perturbar esse fluxo.

Tanto quanto aos humores, a reima associa-se aos problemas a que esses humores estão relacionados e de maneira especial ao sangue e à sua qualidade de ser quente. $\mathrm{O}$ que cria uma tendência de definir reimoso com algo que é quente.

Entretanto, outros elementos devem ser considerados. O alimento forte tem maior tendência a ser reimoso, pois sua força mal usada é agressiva ao organismo. Por outro lado, a relação familiaridade/não familiaridade é importante para definir o potencial de periculosidade de um alimento. $\mathrm{O}$ alimento familiar, próximo e doméstico é considerado saudável ou inofensivo; enquanto o não familiar, distante e selvagem é, ou impróprio para o consumo, ou potencialmente ofensivo.

Aplicado às frutas, esse princípio explica por que elas são consideradas comidas de alto risco. Originárias do quintal ou campo, são usadas cruas, o que aumenta sua distância com relação ao doméstico; não sendo preparadas e sendo consumidas como estão na natureza, as frutas têm, nessa perspectiva, um alto potencial agressivo. Essa relação é confirmada pelo oposto, quando encontramos a afirmação de que a preparação e/ou a forma de criação do animal ou planta destinado a ser usado como alimento funcionam como elementos eliminadores do risco.

Embora lógicas, essas relações não respondem a todas as ocasiões em que uma comida é considerada reimosa. É o potencial de periculosidade de cada alimento que o classificará como reimoso ou não reimoso, independente das qualidades que definem a sua natureza. Os critérios para a definição do que é reimoso se sobrepõem aos demais. É por isso que não se pode dizer simplesmente que um alimento é reimoso como se diz que ele é quente, forte, frio ou fraco. O ser reimoso não é da natureza do alimento em si, não 
é uma qualidade inerente ao alimento, mas associa-se sempre a uma situação: o alimento é reimoso para. Essa parece-me ser a chave da explicação, pois mostra a associação do alimento com o organismo consumidor. $\mathrm{O}$ alimento que é reimoso para uma pessoa, pode não ser para outra; o que é reimoso em uma situação, não será em outra. O reimoso representa a relação individual entre cada organismo e o alimento que ele ingere, o que justificará a expressão muito usada: não como porque é reimoso para mim.

Essa expressão, reimoso para mim, configurará a relação do indivíduo com o alimento e não uma qualidade genérica de uma categoria de alimentos. Podemos encontrar vários exemplos relacionados ao reimoso para, como os alimentos que são considerados reimosos para o período menstrual ou o puerpério e que não são reimosos para a mulher em outras ocasiões, nem são reimosos para o homem. É exatamente essa forma de definir o reimoso que me parece capaz de justificar a falta de uniformidade na classificação desses alimentos. Um mesmo alimento pode ser ou não assim considerado, dependendo da pessoa e ocasião em que ele é capaz de perturbar o fluxo e, conseqüientemente, o equilíbrio dos humores orgânicos.

O que é então reima? A resposta a ser dada é que o alimento não tem reima, ele é reimoso. Isso foi o que despertou minha atenção para o problema da reima. Ao perguntar a qualquer informante se um determinado alimento tinha reima, era logo corrigido com a afirmação: não, ele é reimoso. Inicialmente não foi fácil compreender que havia uma diferença essencial entre a forma de perguntar e o tipo de resposta que sempre era dado. Aos poucos, foi surgindo a idéia de que aí poderia estar um importante elemento analítico, pois, se o alimento não tem reima, o que é e onde está a reima? Essa associação foi se tornando mais clara à medida que apareciam outros dois conceitos fundamentais: o de reima de doença e o de atividades reimosas. A interligação desses conceitos - os informantes eram unânimes em afirmar que não havia diferença entre reima da comida, da doença e de andar a cavalo - levou-me à conclusão de que a reima é relacionada ao organismo e não aos alimentos. Esses, as doenças ou certas atividades provocam a reima, ou seja, interferem no fluxo normal dos humores e geram ou agravam estados patológicos.

Aí está a importância do conceito para se compreender como é vista a questão da saúde, principalmente no que se refere à ideologia da alimentação. As proibições visam proteger o indivíduo em situações em que seu 
organismo está mais sujeito aos riscos de uma agressão externa e existe uma consciência da necessidade de resguardá-lo. A classificação de alimentos ou comportamentos como reimosos, no sentido de que eles são potencialmente agressivos, é, por isso, uma parte essencial do sistema de proibições: ela define um conjunto de alimentos que apresentam risco e que devem ser evitados.

Parece-me estar aí o fio condutor entre esses dois momentos, a medicina grega e os princípios da medicina popular brasileira numa forma de pensar a saúde, a doença e o ato médico, como parte da relação maior entre o homem e a natureza.

\begin{tabular}{|c|c|c|c|c|c|c|c|}
\hline $\begin{array}{c}\text { As } \\
\text { qualidades }\end{array}$ & $\begin{array}{c}\text { Os quatro } \\
\text { elementos }\end{array}$ & $\begin{array}{c}\text { As quatro } \\
\text { partes do } \\
\text { mundo }\end{array}$ & $\begin{array}{c}\text { Os } \\
\text { quatro } \\
\text { ventos }\end{array}$ & $\begin{array}{c}\text { As quatro } \\
\text { partes do } \\
\text { ano }\end{array}$ & $\begin{array}{c}\text { Os quatro } \\
\text { humores }\end{array}$ & $\begin{array}{c}\text { As quatro } \\
\text { idades }\end{array}$ & $\begin{array}{c}\text { Os doze } \\
\text { signos }\end{array}$ \\
\hline $\begin{array}{c}\text { Quente e } \\
\text { úmido }\end{array}$ & Ar & Meio-Dia & Sul & Primavera & Sangue & Infância & $\begin{array}{c}\text { Gêmeos, } \\
\text { Libra e } \\
\text { Aquário }\end{array}$ \\
\hline $\begin{array}{c}\text { Quente e } \\
\text { seco }\end{array}$ & Fogo & Oriente & Leste & Estio & Cólera & Juventude & $\begin{array}{c}\text { Carneiro, } \\
\text { Leão e } \\
\text { Sagitário }\end{array}$ \\
\hline $\begin{array}{c}\text { Frio e } \\
\text { úmido }\end{array}$ & Água & Ocidente & Oeste & Outono & Fleuma & Velhice & $\begin{array}{c}\text { Câncer, } \\
\text { Escorpião e } \\
\text { Peixes }\end{array}$ \\
\hline $\begin{array}{c}\text { Frio e } \\
\text { seco }\end{array}$ & Terra & Setentrião & Norte & Inverno & Melancolia & Decrepitude & $\begin{array}{c}\text { Touro, } \\
\text { Virgem e } \\
\text { Capricórnio }\end{array}$ \\
\hline
\end{tabular}

Cortez, [s.d.], p. 23

\section{Referências}

BRANDÃO, Carlos Rodrigues. Mossâmedes: crenças e costumes de comidas. Goiânia: Editora da Universidade Federal de Goiás, 1976.

CALDER, Ritchie. O homem e a medicina. São Paulo: Hemus, 1976.

CASTRO RODRIGUES, Gilda. Reses e homens: um estudo de práticas terapêuticas numa comunidade rural. Dissertação (Mestrado)-Programa de Pós-Graduação em Antropologia da Universidade de Brasília, Brasília, 1979.

CORTEZ, Jeronymo. Lunario e prognostico perpetuo. Porto: Lello \& Irmão, [s.d.]. CURRIER, Richard L. The hot-cold syndrom and symbolic balance Mexican and Spanish-American folk medicine. Ethnology, n. 5, 1966. 
FOSTER, George. Relationships between Spanish and Spanish-American folk medicine. Journal of American Folklore, n. 65, 1953.

Disease etiologies in non-western medical systems. American Anthropologist, v. 78, n. 4, 1976.

GRECO RODRIGUES, Antônio. Alimentação e saúde: um estudo da ideologia da alimentação. Dissertação (Mestrado)-Programa de Pós-Graduação em Antropologia da Universidade de Brasília, Brasília, 1978.

LLOYD, Geoffrey E. R. The hot and the cold, the dry and the wet in greek philosophy. Journal Of Helenic Studies, n. 84, 1964.

LOGAN, Michael H. Humoral medicine in Guatemala and peasant acceptance of modern medicine. Human Organization, v. 32, n. 4, 1973.

POLGAR, Steven. Health action in cross-cultural perspective. In: FREEMAN, Lavine (Org.) Handbook of medical sociology, 1963.

SANTOS FILHO, Lycurgo de Castro. História geral da medicina brasileira. São Paulo: Hucitec: Edusp, 1977.

TAYLOR, Henry O. Greek biology and medicine. New York: Cooper Square Publishers Inc., 1963. 